\title{
Adjuvant effect of anti-idiotypic antibodies to Yersinia pestis lipopolysaccharide
}

\author{
V. A. FEODOROVA, Z. L. DEVDARIANI and L. S. NAZAROVA \\ Russia State Antiplague Research Institute 'Microbe', Saratov, Russia
}

\begin{abstract}
Rabbit anti-idiotypic antibodies (anti-Id-ab) against Yersinia pestis lipopolysaccharide (LPS) were obtained with monoclonal immunoglobulins. Their complementary character to the original antigen was confirmed by immunohistochemical analysis and ELISA and gel precipitation tests. The anti-Id-ab were shown to possess all essential properties of Ab2 $\beta$ subtype. Both in-vitro and in-vivo experiments demonstrated a pronounced adjuvant activity of anti-Id-ab without the toxic effect characteristic of $Y$. pestis LPS. Combined immunisation with anti-Id-ab plus the FI capsular antigen led to a significant increase in the protective immune response against experimental acute challenge with virulent $Y$. pestis.
\end{abstract}

\section{Introduction}

Immunity to plague is correlated with the presence of antibody to the capsular antigen (Fraction I antigen, FI) [1] and immunisation with FI induces protection against the disease in animal models [2-4]. Although FI is a protective antigen, studies have shown that it is not required for virulence in mice, raising the possibility that it is not an ideal vaccine candidate $[5,6]$. At the same time, immunisation with FI in the presence of adjuvants provides a high degree of protection [7]. The lipopolysaccharides (LPS) of many gram-negative bacteria demonstrate pronounced adjuvant properties [8-10]; however, immunomodulating activity of Yersimia pestis LPS has not been shown. Its high toxicity discourages its application as a component of a plague vaccine $[11,12]$. Furthermore, attempts to detoxify the LPS by acid or alkali treatment and other methods were of limited success [13]. Antiidiotypic antibodies (anti-Id-ab) against $Y$. pestis LPS offer a convenient model for studying the biological properties of the original antigen. Anti-Id-ab provides a protein equivalent of any bacterial antigen and such mimicry of immunogenic polysaccharide and lipid epitopes makes it possible to present their antigenic determinants to the immune cells and to obtain effective immunity [14-17]. The aims of this study were to obtain anti-Id-ab against $Y$. pestis LPS by the use of monoclonal antibodies (MAbs), to establish their

Received 8 June 1998; revised version received 1 Oct. 1998; accepted 5 Oct. 1998.

Corresponding author: Dr V. A. Feodorova (e-mail: postmaster@microbe.saratov.su). specific complementarity to the original antigen, to study their antigenic and adjuvant properties in combined immunisation with FI and anti-Id-ab against $Y$. pestis LPS and to compare their protective properties with those of the native antigen.

\section{Materials and methods}

\section{Preparation of anti-Id-ab and anti-anti-Id-ab}

Murine BALB/c MAbs (IgG1) against $Y$. pestis LPS secreted by the Yp. $\mathrm{A}_{6} . \mathrm{Sp}$. hybridoma were used to induce anti-Id-ab [18]. Rabbits were given five intravenous injections of $1 \mathrm{mg}$ of MAbs separated by 3-day intervals and were exsanguinated 7 days after the last dose. Immunoglobulins were isolated from the serum with ammonium sulphate $45 \%$ saturated solution, followed by purification through Sephadex G-50. Anti-anti-Id-ab were raised in six groups of 10 inbred CBA and C57/B1 6-8-week-old female mice given three intraperitoneal doses of rabbit anti-Id-ab according to the schedule: group 1, $0.1 \mathrm{mg}$; group 2, $0.5 \mathrm{mg}$; group 3, $1.0 \mathrm{mg}$; group 4, $2.5 \mathrm{mg}$; group 5, $5.0 \mathrm{mg}$ and group $6,10 \mathrm{mg}$. Anti-anti-Id-ab were isolated from the mouse sera collected on the 14th day after the third immunisation by ammonium sulphate precipitation as described above.

\section{Bacterial strains}

The strains used included $110 \mathrm{Y}$. pestis strains isolated from natural plague foci in the Community of Independent States (CIS), Mongolia, China, Vietnam, Pakistan, India, Africa and South America, and $15 Y$. 
pestis strains constructed by genetic modification and harbouring different combinations of their innate plasmids [19], 65 Y. pseudotuberculosis strains (serovars I-VI), 12 Y. enterocolitica strains, 10 Escherichia coli strains, 10 Salmonella strains, 8 Shigella strains, and 5 Proteus strains. Y. pestis virulent strain 231 was used to study the adjuvant properties of anti-Id-ab in protection experiments. One LD50 for mice of $Y$. pestis strain 231 was 50 cells. The bacteria were cultured on Hottinger agar (pH 7.2-7.4) incubated at $28^{\circ} \mathrm{C}$ for $48 \mathrm{~h}$.

\section{FI preparation}

FI was isolated from supernatant fluid of $Y$. pestis strain $E V$ broth culture, incubated at $28^{\circ} \mathrm{C}$ for $48 \mathrm{~h}$, with subsequent purification in Ultragel AcA-22 (LKB). Chemical analyses showed that the FI preparation contained proteins $99.1 \pm 0.2 \%$, polysaccharides $<0.01 \%$ and lipids $<0.04 \pm 0.002 \%$ [20].

\section{Immunodiffusion tests}

Immunodiffusion in gel was performed according to Ouchterlony [21] with $Y$. pestis LPS, MAbs against LPS and anti-Id-ab.

\section{Enzyme-linked immunosorbent assay (ELISA)}

Several modifications of ELISA were used for serological comparison of anti-Id-ab and $Y$. pestis LPS.

Direct double antibody sandwich ELISA. ELISA plates (96-well) were sensitised (per well) with $100 \mu 1$ of anti$Y$. pestis LPS MAbs in phosphate-buffered saline (PBS) at $10 \mu \mathrm{g}$ of protein $/ \mathrm{ml}$ and incubated overnight at $4^{\circ} \mathrm{C}$. The wells were washed three times with washing buffer (PBS containing Tween-20 0.05\%). The wells were then saturated with BSA $1 \%$ in PBS for $1 \mathrm{~h}$ at $37^{\circ} \mathrm{C}$ and washed as above. Then, dilutions containing antiId-ab or $Y$. pestis LPS $1.0 \mathrm{mg}-0.5 \mathrm{ng} / \mathrm{ml}$ were added and the plates were re-incubated for $1 \mathrm{~h}$ at $37^{\circ} \mathrm{C}$. After washing, peroxidase-labelled MAbs against $Y$. pestis LPS diluted in diluting buffer (BSA $1 \%$ in PBS) were added and the plates were incubated for $1 \mathrm{~h}$ at $37^{\circ} \mathrm{C}$. The wells were washed six times and the substrate solution containing 2,2'-azino-bis(3-ethylbenzthiazoline sulphonic acid) $22.3 \mathrm{mg} / \mathrm{ml}, \mathrm{H}_{2} \mathrm{O}_{2} \quad 0.0003 \%$ in citrate buffer (0.05 M, pH 4.4) was added (100 $\mu \mathrm{l} /$ well). The plates were incubated for $30 \mathrm{~min}$ at room temperature and the $\mathrm{OD}_{405}$ was measured with a multi-channel ELISA plate reader.

Indirect double antibody sandwich ELISA. ELISA plates (96-well) were sensitised with (per well) $100 \mu \mathrm{l}$ of equine anti-Y. pestis IgG, rabbit and guinea-pig IgG against $Y$. pestis LPS at equal protein concentrations of $10 \mu \mathrm{g} / \mathrm{ml}$. The following procedures were performed as described above.

Indirect ELISA. The plates were sensitised with (per well) $100 \mu \mathrm{l}$ of normal mouse IgG at $10 \mu \mathrm{g} / \mathrm{ml}$ protein concentration. Then, dilutions containing anti-Id-ab $1.0 \mathrm{mg}-0.5 \mathrm{ng} / \mathrm{ml}$ were added. Peroxidase-labelled anti-rabbit immunoglobulins were used as detection conjugate. The wells were washed and blocked and screened as described above.

Indirect ELISA was also used for studying the specificity of anti-anti-Id-ab. The plates were sensitised with (per well) $100 \mu \mathrm{l}$ of suspension containing $1 \times 10^{9}$ cells of different bacterial strains in $1 \mathrm{ml}$ of PBS. Then, anti-anti-Id-ab diluted 1 in 100 in PBS was added. Peroxidase-labelled anti-mouse IgG was used as a detection conjugate.

\section{Immunohistochemical method}

To elucidate LPS-specific antigenic determinants in the spleen, the test group of 60 female BALB/c mice was immunised with the anti-Id-ab described above, while the control group of these mice received five intraperitoneal $2.5-\mathrm{mg}$ doses of normal rabbit immunoglobulins with 14-day intervals between the inoculations. At 14 days after the fifth immunisation, the spleen was excised and fixed in formaldehyde $10 \%$ solution. Paraffin-embedded sections cut with a microtome were prepared after additional fixation in cold ethanol $80 \%$. For the immunohistochemical studies the sections were treated with fluorescent MAbs against $Y$. pestis LPS diluted 1 in 64 to reveal LPS-specific antigenic determinants and with fluorescent anti-rabbit guinea-pig immunoglobulins diluted 1 in 8 to reveal rabbit immunoglobulins for control. The specimens were examined by fluorescence microscopy (ML-2, Lomo, Russia).

\section{Assessment of in-vitro activity of anti-Id-ab and LPS}

The biological activity of anti-Id-ab against $Y$. pestis LPS and of the antigen itself was studied in vitro with a B-cell hybridoma, Yp.FI.B . $_{2}$. Sp., which secreted MAbs to the FI of the plague bacteria [22]. Rabbit anti-mouse immunoglobulins were used to control for the specificity of anti-Id-ab activity. After sterilisation through nitrocellulose membranes $(0.22 \mu \mathrm{m}$ pore diameter) $1.0-0.001-\mathrm{mg}$ preparations were inoculated into 48-well Costar culture plates containing $5 \times 10^{4}$ hybridoma cells/well. The cells were incubated in RPMI- 1640 medium with fetal calf serum $15 \%$ at $37^{\circ} \mathrm{C}$ and $\mathrm{CO}_{2} 5 \%$ in air. The number of cells was evaluated on the sixth day with a haemocytometer. Each preparation was inoculated into 24 wells.

$\mathrm{CBA}$ and $\mathrm{C} 57 / \mathrm{Bl}$ mice $(\mathrm{n}=102)$ were used to study the anti-Id-ab adjuvant properties in vivo. The mice were divided into three groups of 34 and immunised with $50 \mu \mathrm{g}$ of: (i) FI only; (ii) FI + RAM, combined immunisation with FI and rabbit anti-mouse immunoglobulins; (iii) FI + anti-Id-ab, combined immunisation 
with FI and anti-idiotypic antibodies against $Y$. pestis LPS. Unimmunised mice were used as a control. At 14 days after the last immunisation, all mice received an acute subcutaneous challenge with 50 LD50 of virulent $Y$. pestis strain 231 . The efficiency of immunisation was estimated from the proportion of dead mice.

\section{Statistical analysis}

Statistical analysis of the results of assays for anti-Id-ab adjuvant activity in vitro and in vivo was performed according to Ashmarin and Vorob'ov [23].

\section{Results}

Anti-Id-ab produced a single well-defined precipitation line with MAbs to $Y$. pestis LPS diluted 1 in 64 in the immunodiffusion gel precipitation assay. The original antigen, LPS at $1 \mathrm{mg} / \mathrm{ml}$, diluted 1 in 128 , gave a precipitation reaction with specific MAbs. Anti-Id-ab reacted with normal mouse IgG at titres of 4-8.

In the direct sandwich variant of ELISA test, anti-Id-ab detected MAbs against $Y$. pestis LPS down to $12 \mathrm{ng} / \mathrm{ml}$ and normal mouse immunoglobulins down to $2 \mu \mathrm{g} / \mathrm{ml}$ in indirect ELISA. Anti-Id-ab to LPS and $Y$, pestis LPS were determined in a similar concentration, $2 \mathrm{ng} / \mathrm{ml}$, in indirect double antibody sandwich ELISA with rabbit, equine and guinea-pig IgG against $Y$. pestis LPS. Nonspecific cross-reactivity among the immunologically active components used in ELISA was excluded.

MAbs against $Y$. pestis LPS (Ab1) identified all strains of $Y$. pestis with different plasmid profiles grown at $28^{\circ} \mathrm{C}$ or $37^{\circ} \mathrm{C}$ as well as $30 \%$ of $Y$. pseudotuberculosis strains [24]. Anti-anti-Id-ab also responded to all $Y$. pestis strains and the same $30 \%$ of $Y$. pseudotuberculosis strains, but gave no reaction with $Y$. enterocolitica or other Enterobacteriaceae strains (Table 1).

The immune sera of all the mice immunised with antiId-ab irrespective of the dose reacted specifically with $Y$. pestis LPS (Fig. 1). The highest antibody titre, 64000 , was registered after the mice had been immunised with $0.1 \mathrm{mg}$ of anti-Id-ab. This dose also induced antibody formation at titres of 8000-16000. Other concentrations of the preparation led to the release of antibodies active at dilutions from 1 in 640

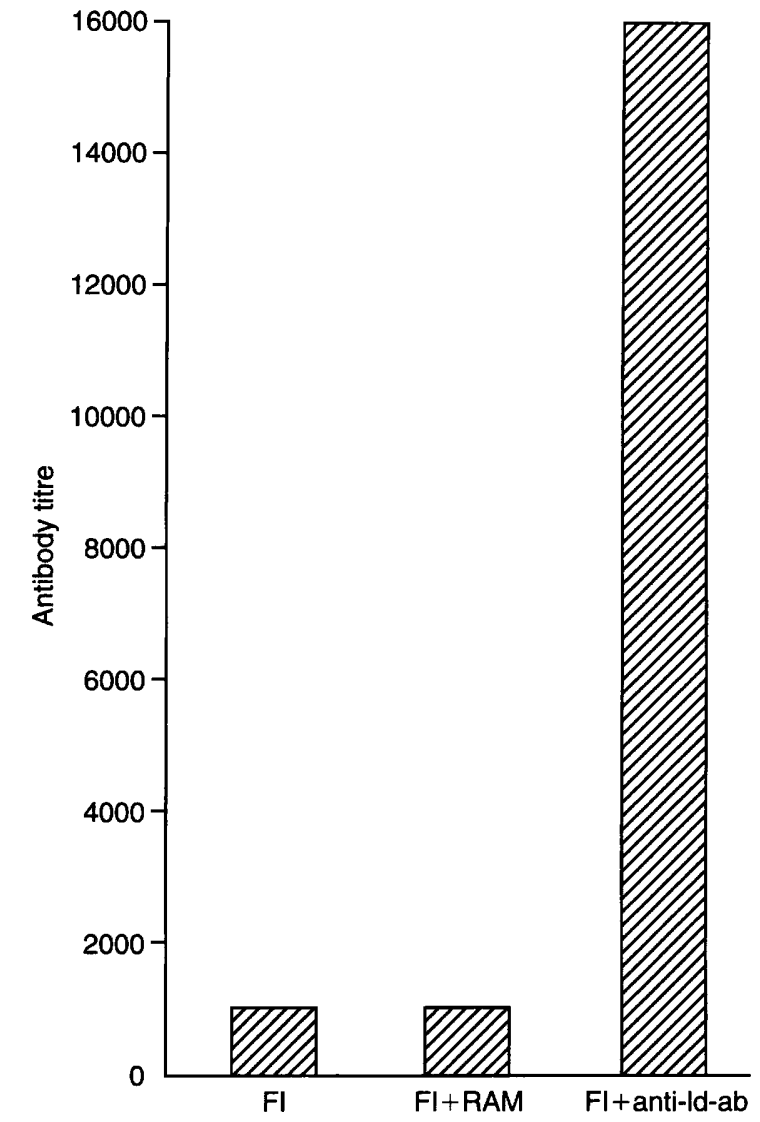

Fig. 1. Titres of antibodies against $Y$. pestis capsular antigen (FI) in mice. FI, immunised with only the capsular antigen; FI + RAM, combined immunisation with FI and rabbit anti-mouse immunoglobulins; FI + anti-Id-ab, combined immunisation with FI and anti-idiotypic antibodies to $Y$. pestis LPS.

$(2.5 \mathrm{mg})$ to 1 in $400(0.5,5.0,10.0 \mathrm{mg})$. The highest specific activity (titre 128000) was observed with immune sera from the animals that had received $1.0 \mathrm{mg}$ of anti-Id-ab.

Fluorescence microscopy with FITC-labelled antibodies against normal rabbit immunoglobulins in the spleens of control mice revealed many antibody-containing cells (lymphoblasts and plasmacytes) with brightly fluorescent cytoplasm. No antibodies to rabbit immunoglobulins were found in test animals. On the other hand, when fluorescent MAbs against $Y$. pestis LPS were used, antigen-containing cells specific for $Y$. pestis LPS were registered in this group of mice.

Table 1. Comparison of specific properties of anti-anti-Id-ab and MAbs against $Y$. pestis LPS

\begin{tabular}{lccc}
\hline & Number of & \multicolumn{2}{c}{ Number of strains identified in indirect ELISA by } \\
\cline { 3 - 4 } Bacterial & strains & Anti-anti-Id-ab & MAbs \\
\hline$Y$. pestis & 110 & 110 & 110 \\
$Y$ pseudotuberculosis & 31 & 9 & 9 \\
$Y$. enterocolitica & 13 & 0 & 0 \\
Other micro-organisms & 21 & 0 & 0 \\
\hline
\end{tabular}

* See Materials and methods. 
A comparative study of the LPS and anti-Id-ab against $Y$. pestis LPS with regard to their biological activity showed $Y$. pestis LPS to be highly toxic for B-cell hybridomas (Table 2). This preparation added to the wells to give final concentrations of $5-100 \mu \mathrm{g} / \mathrm{ml}$ inhibited cell proliferation, in contrast to those without LPS $(\mathrm{p}<0.05)$. The indices of proliferation were 0.26 $(\mathrm{SEM} 0.01) \times 10^{6}$ cells $/ \mathrm{ml}$ and $0.10($ SEM 0.01$) \times 10^{6}$ cells $/ \mathrm{ml}$, respectively. Larger LPS concentrations resulted in the complete death of hybridoma cells. The presence of anti-Id-ab $5-50 \mu \mathrm{g} / \mathrm{ml}$ in the culture medium stimulated 5-6-fold greater hybridoma growth than that of the control cells, i.e. (1.74 SEM $0.02-2.98 \mathrm{SEM} 0.4) \times 10^{6} \mathrm{cells} / \mathrm{ml}(\mathrm{p}<0.001)$; antiId-ab $0.1-1.0 \mathrm{mg} / \mathrm{ml}$ increased growth rate $10-12-$ fold, (3.59 SEM 0.04-4.20 SEM 0.03) $\times 10^{6}$ cells $/ \mathrm{ml}$ $(p<0.001)$. The number of cells after the addition of analogous concentrations of normal rabbit anti-mouse immunoglobulins did not exceed the control values (0.33 SEM $0.01-0.37$ SEM 0.01$) \times 10^{6}$ cells $/ \mathrm{ml}$ $(\mathrm{p}>0.05)$.

The antibody response after three subsequent immunisations of $\mathrm{CBA}$ and $\mathrm{C} 57 / \mathrm{Bl}$ mice with $Y$. pestis capsular antigen (FI) and $50 \mu \mathrm{g}$ of anti-Id-ab was studied (Fig. 1). The mean specific antibody titre in mice treated with FI only was 1000 . When this antigen was inoculated simultaneously with anti-Id-ab, the titre increased to 16000 . In the control group of mice, immunised with FI and rabbit anti-mouse immunoglobulins, the levels of anti-capsular antibodies were almost the same as those in the animals immunised with the capsular antigen alone.
The results of an acute challenge with 50 LD50 of virulent $Y$. pestis strain 231 in three groups of mice (i) immunised with FI only; (ii) immunised with FI + RAM; (iii) immunised with FI + anti-Id-ab - are shown in Table 3 . Immunisation of mice with FI alone protected 47.0 SEM $8.6 \%$ of animals. The same level of protection was observed in the group of mice immunised with FI + RAM. FI + anti-Id-ab immunisation led to a significant increase in survival of mice challenged with 50 LD50 of $Y$. pestis strain 231 . In this group, the number of deaths was half that in the group of mice inoculated with FI alone or FI plus normal rabbit anti-mouse immunoglobulins $(p<0.01)$. The highest level of protection among the mice immunised with FI + anti-Id-ab correlated with the highest specific antibody titre to FI.

\section{Discussion}

According to Jerne [25] the immune system is a set of Id $(\mathrm{Ab} 1)$ and anti-Id (Ab2) that interact with each other. At present $\mathrm{Ab} 2 \alpha, \mathrm{Ab} 2 \beta, \mathrm{Ab} 2 \gamma$ and $\mathrm{Ab} 2 \varepsilon$ are known. Only a certain type of anti-idiotypic antibodies $(\mathrm{Ab} 2 \beta)$ has the property of bearing the internal image of an original antigen [26,27]. Such antibodies have been used successfully for induction of highly protective antibody responses against parasites, bacteria and viruses [28-31]. It is known that the LPS of gramnegative bacteria may increase T- and B-cell proliferation [8-10], but no information about the immunomodulating properties of $Y$. pestis LPS has been reported. The use of the relevant anti-Id-ab may help to reveal

Table 2. Effect of anti-Id-ab and $Y$. pestis LPS on B-cell hybridoma proliferation in vitro

\begin{tabular}{|c|c|c|c|c|c|c|}
\hline \multirow{2}{*}{$\begin{array}{l}\text { Dose of preparation } \\
(\mu \mathrm{g} / \mathrm{ml})\end{array}$} & \multicolumn{6}{|c|}{ Mean (SEM) hybridoma cell concentrations $\left(10^{6} / \mathrm{ml}\right.$ of culture medium) after addition of } \\
\hline & LPS & $\mathrm{p}$ value & anti-Id-ab & $\mathrm{p}$ value & RAM & $\mathrm{p}$ value \\
\hline 1 & $0.30(0.04)$ & $>0.05$ & ND & & ND & \\
\hline 5 & $0.26(0.01)$ & $<0.05$ & $1.74(0.02)$ & $<0.001$ & $0.33(0.01)$ & $>0.05$ \\
\hline 10 & $0.26(0.01)$ & $<0.05$ & $1.85(0.02)$ & $<0.001$ & $0.34(0.02)$ & $>0.05$ \\
\hline 25 & $0.25(0.01)$ & $<0.05$ & $2.51(0.04)$ & $<0.001$ & $0.34(0.02)$ & $>0.05$ \\
\hline 50 & $0.22(0.01)$ & $<0.05$ & $2.98(0.04)$ & $<0.001$ & $0.33(0.01)$ & $>0.05$ \\
\hline 100 & $0.10(0.01)$ & $<0.01$ & $3.59(0.04)$ & $<0.001$ & $0.36(0.02)$ & $>0.05$ \\
\hline 200 & - & & $3.68(0.03)$ & $<0.001$ & $0.37(0.01)$ & $>0.05$ \\
\hline 400 & - & & $4.19(0.04)$ & $<0.001$ & $0.35(0.01)$ & $>0.05$ \\
\hline 1000 & - & & $4.20(0.03)$ & $<0.001$ & $0.35(0.01)$ & $>0.05$ \\
\hline Control (no preparation added) & $0.35(0.01)$ & & ND & & ND & \\
\hline
\end{tabular}

$\mathrm{ND}$, not done.

- , only dead hybridoma cells.

Table 3. Adjuvant properties of anti-idiotypic antibodies against $Y$. pestis LPS in mice infected with a virulent $Y$. pestis strain

\begin{tabular}{lccr}
\hline $\begin{array}{l}\text { Antigens } \\
\text { use in } \\
\text { immunisation }\end{array}$ & $\begin{array}{c}\text { Number } \\
\text { of mice }\end{array}$ & $\begin{array}{c}\text { Challenge } \\
\text { dose } \\
\text { (LD50) }\end{array}$ & Number (\%) of dead mice \\
\hline FI only & 34 & 50 & $16(47.0$ SEM 8.6) \\
FI + RAM & 34 & 50 & $15(44.1$ SEM 8.5) \\
FI + anti-Id-ab & 34 & 50 & $8(23.5$ SEM 4.6) \\
Control (unimmunised) & 10 & 50 & $10(100)$ \\
\hline
\end{tabular}


such properties of this antigen. In the current study, rabbit anti-Id-ab against $Y$. pestis LPS were obtained by the use of MAbs. The pool of rabbit immunoglobulins contained antibodies to both the non-specific moiety of mouse immunoglobulins and the LPS idiotype; however, anti-Id-ab against LPS predominated. Several methods were used to define their subtype and complementary character to the antigen. The results of ELISA cross-reactions and the immunodiffusion gel precipitation test provided evidence for anti-Id-ab complementarity to the original antigen.

As the inhibition of binding of the Id to the antigen is a characteristic of both $\mathrm{Ab} 2 \beta$ (internal image) and $\mathrm{Ab} 2 \gamma$, $\mathrm{Ab} 2 \beta$ and $\mathrm{Ab} 2 \gamma$ were distinguished by their ability to bind Id in xenogenic antisera specific for $Y$. pestis LPS (equine, rabbit and guinea-pig). $\mathrm{Ab} 2 \beta$ are able to recognise $A b 1$ produced in animals of other species, whereas $\mathrm{Ab} 2 \gamma$ are not. In the current study, anti-Id-ab and the antigen itself, $Y$. pestis LPS, were shown to react with equine, rabbit and guinea-pig antisera against $Y$. pestis LPS in equal concentration. This suggests that the anti-Id-ab obtained belonged to $\mathrm{Ab} 2 \beta$.

One of the most significant properties of $\mathrm{Ab} 2 \beta$ is their ability to induce the synthesis of anti-anti-Id-ab which demonstrate the same activity as Ab1. The anti-Id-ab used in the current study for immunisation of mice produced immune murine sera that contained high levels of anti-anti-Id-ab that recognised the original antigen, $Y$. pestis LPS. The specific activity of mouse anti-anti-Id-ab was dependent on the immunising dose of the antigen. High anti-anti-Id-ab titres in the animals treated with anti-Id-ab are likely to reflect powerful antigenic activity of $Y$. pestis LPS, because only a strong antigen can induce the production of specific antibodies against its idiotype. Comparison of specific properties of MAbs against $Y$. pestis LPS (Ab1) and anti-anti-Id-ab showed their complete coincidence. Both antibodies identified $Y$. pestis strains with different plasmid profiles as well as strains of $Y$. pseudotuberculosis and did not react with other species of Enterobacteriaceae. This strongly suggests that the antiId-ab obtained were of $\mathrm{Ab} 2 \beta$ subtype.

One essential criterion for defining an anti-Id-ab as an internal image of an antigen is mimicry of its biological activity. Therefore, after the anti-Id-ab subtype was determined, the biological properties and adjuvant activity were studied. The following approaches were used: (i) anti-Id-ab influence upon Bcell hybridomas in vitro; (ii) the level of murine antibody response after combined immunisation with FI and anti-Id-ab; (iii) protection in vivo after combined immunisation with $\mathrm{FI}+$ anti-Id-ab in the acute challenge with a virulent strain of $Y$. pestis. Addition of anti-Id-ab against $Y$. pestis LPS to the growth medium increased B-cell hybridoma proliferation 5-6-fold, whereas the original antigen (LPS) was extremely toxic for these cells, killing them even in minute concentrations. This observation indicates that $Y$. pestis LPS possesses the immunomodulating activity inherent in LPS of other gram-negative bacteria [8-10].

The stimulating effect of anti-Id-ab on lymphoid cells served as the basis for the in-vivo experiments. Significantly higher levels of murine antibodies (antianti-Id-ab) in the animals immunised with FI and antiId-ab conjointly, in comparison with FI-treated mice, were observed. This is important evidence of the adjuvant properties of anti-Id-ab. Immunomodulating (adjuvant) activity of anti-Id-ab was also confirmed by the results of an acute challenge. CBA and C57/B1 mice were used, as it had been shown earlier that mice of these strains are the most susceptible to plague and they are the most convenient experimental model for studying the protective properties of $Y$. pestis antigens [32]. Preliminary titration showed that the optimal dose was $0.1 \mathrm{mg}$. The number of surviving mice after the combined immunisation with FI and anti-Id-ab was twice that of the groups of mice immunised without anti-Id-ab. Correlation of high titres of specific murine antibodies (anti-anti-Id-ab) with the highest level of protection in the group of mice immunised with FI + anti-Id-ab confirms the immunomodulating properties of anti-Id-ab.

The 'in-vitro/in-vivo' system developed for studying adjuvant properties of anti-Id-ab against $Y$. pestis LPS was very convenient and allowed the identification of the anti-Id-ab as carrier of the 'internal image' of the original antigen. It should be emphasised that, in contrast to the highly toxic $Y$. pestis LPS (LD50 for mice, $130 \mu \mathrm{g}$ ), anti-Id-ab did not have this activity, as doses of $10 \mathrm{mg}$ of anti-Id-ab inoculated into the mice to induce anti-anti-Id-ab did not kill the animals. In contrast to LPS, anti-Id-ab did not contain pathogenic material and did not cause death in mice in doses 80 times higher than the toxic concentration of LPS. This strategy may be useful for increasing the immunogenicity of FI and may be applicable to other LPS [33-35]. These results provide evidence of the immunomodulating properties of anti-Id-ab.

Immunohistochemical staining with anti-Id-ab provided presumptive evidence of the tissue localisation of endotoxin (LPS)-target cells. The specific receptors for this antigen appeared to be located in the cytoplasm of plasmacytes, in the B-zones of murine spleen. These data correspond with those obtained by others [36] after immunisation with $Y$. pestis LPS.

In summary, rabbit polyclonal anti-idiotypic antibodies were generated against $Y$. pestis LPS by immunisation with MAbs against this antigen. These anti-Id-ab were directed predominantly against an Id and possessed the properties of $\mathrm{Ab} 2 \beta$. The observed adjuvant activities of the anti-Id-ab in a murine model demonstrated the possibility of increasing the protective immune re- 
sponse against plague by combined immunisation with FI + anti-Id-ab.

We thank N. Teryoshkina and K. Lobanov for help on preparing the manuscript.

\section{References}

1. Williams JE, Arntzen L, Tyndal GL, Isaäcson M. Application of enzyme immunoassays for the confirmation of clinically suspect plague in Namibia, 1982. Bull World Health Organ 1986; 64: 745-752.

2. Meyer KF, Hightower JA, McCrumb FR. Plague immunization. VI. Vaccination with the fraction 1 antigen of Yersinia pestis. $J$ Infect Dis 1974; 129: S41-S45.

3. Simpson WJ, Thomas RE, Schwan TG. Recombinant capsular antigen (fraction 1) from Yersinia pestis induces a protective antibody response in Balb/c mice. Am J Trop Med Hyg 1990; 43: 389-396.

4. Williamson ED, Eley SM, Griffin KF et al. A new improved sub-unit vaccine for plague: the basis of protection. FEMS Immunol Med Microbiol 1995; 12: 223-230.

5. Drozdov IG, Anisimov AP, Samoilova SV et al. Virulent noncapsulate Yersinia pestis variants constructed by insertion mutagenesis. J Med Microbiol 1995; 42: 264-268.

6. Perry RD, Fetherston JD. Yersinia pestis - etiologic agent of plague. Clin Microbiol Rev 1997; 10: 35-66.

7. Andrews GP, Heath DG, Anderson GW, Welkos SL, Friedlander AM. Fraction 1 capsular antigen (F1) purification from Yersinia pestis $\mathrm{CO} 92$ and from an Escherichia coli recombinant strain and efficacy against lethal plague challenge. Infect Immun 1996; 64: 2180-2187.

8. Allison AC, Byars NE. Immunological adjuvants: desirable properties and side-effects. Mol Immunol 1991; 28: 279-284.

9. Baldwin $\mathrm{CL}$, Winter AJ. Blastogenic response of bovine lymphocytes to Brucella abortus lipopolysaccharide. Infect Immun 1985; 47: 570-572.

10. Coleman DK, Culver KE, Ryan JL. Effect of lipopolysaccharide on the stimulation of macrophage Fc-dependent phagocytosis by splenic B lymphocytes. Cell Immunol 1985; 91: $520-527$.

11. Frolov AF, Ruban NM, Vasyurenko ZP. Fatty acid composition of lipopolysaccharides of the strains of different species of Yersinia. Z Hyg Epidemiol Microbiol Immunol 1989; 33: 55-61.

12. Walker RV. Comparative physiopathology of plague endotoxin in mice, guinea-pigs and monkeys. $J$ Infect Dis 1968; 118: $188-196$.

13. Gooseva IP. Liposome forms of Yersinia pestis immunogens. $\mathrm{PhD}$ Thesis. Russia State Antiplague Research Institute 'Microbe', Saratov, Russia. 1995.

14. Westernik MAJ, Apicella MA. Anti-idiotypic antibodies as a vaccine against carbohydrate antigens. Springer Semin Immunopathol 1993; 15: 227-234.

15. Chanh TC, Hewetson JF. Polyclonal anti-idiotypes induce antibody responses protective against ricin cytotoxicity. Immunology 1993; 79: 681-684.

16. Cornelissen $\mathrm{JJ}$, Maassen $\mathrm{K}$, van Emst $\mathrm{L}$ et al. Anti-idiotypic immunization provides protection against lethal endotoxaemia in BALB/c mice. Immunology 1993; 79: 673-680.

17. Field SK, Morrison DC. An anti-idiotypic antibody which mimics the inner-core region of lipopolysaccharide protects mice against a lethal challenge with endotoxin. Infect Immun 1994; 62: 3994-3999.

18. Devdariani ZL, Verenkov MS, Feodorova VA, Solodovnicov NS, Belov LG. Identification of Yersinia pestis with varied plasmid composition using monoclonal and polyclonal fluor- escent immunoglobulins. FEMS Immunol Med Microbiol 1993; 6: $31-35$.

19. Protsenko OA, Filippov AA, Kutyrev W. [Plasmid heterogeneity in populations of Yersinia pestis strains.] Mol Gen Mikrobiol Virusol 1992; (3-4): 20-24.

20. Anisimov PI, Serdobintsev LN, Ivanov IUV, Taranenko TM, Naumov AV. [Various physico-chemical properties of the Yersinia pestis capsular protein.] Mol Gen Mikrobiol Virusol 1987; (2): 24-27.

21. Ouchterlony Ö. Antigen-antibody reactions in gels. Types of reactions in coordinated systems of diffusion. Acta Pathol Microbiol Scand 1953; 32: 231-240.

22. Anisimov PI, Kuznetsova KA, Devdariani ZL et al. Results of research devoted to constructing of plague luminescence diagnostic anticapsular serum based on $\mathrm{McAb}$ against Yersinia pestis Fraction I. In: Diagnostics and prophylaxis of particularly dangerous diseases. Saratov, Russia. 1983: 3-8.

23. Ashmarin IP, Vorob'ov AA. Statistical methods in microbiological research. Leningrad, State Press of Medical Literature. 1962: 10-104.

24. Devdariani ZL, Feodorova VA, Solodovnikov NS et al. ELISA test system for identification of typical and atypical plague microbe strains. Med Parasitol Parasite Dis 1997; 1: 31-34.

25. Jerne NK. Towards a network theory of the immune system. Ann Immunol 1974; 125: 373-389.

26. Kresina TF, Olds GR. Antiidiotypic antibody vaccine in murine Schistosomiasis mansoni comprising the internal image of antigen. $J$ Clin Invest 1989; 83: 912-920.

27. Li J-L, Chen J-L, Ouyang M-N et al. Immunization strategies for the production of rat monoclonal anti-idiotype antibodies. $J$ Immunol Methods 1991; 142: 15-20.

28. Grsych J-M, Rousse-Velge F, Capron A. Use of anti-idiotypic antibodies in approaches to immunoprophylaxis of schistosomiasis. In: Langone $\mathrm{J}$ (ed) Antibodies, antigens and molecular mimicry. San Diego, Academic Press. 1989: Methods Enzymol 178: $390-404$.

29. Schreiber JR, Nixon KL, Tosi MF, Pier GB, Patawaran MB. Anti-idiotype-induced, lipopolysaccharide-specific antibody response to Pseudomonas aeruginosa. II. Isotype and functional activity of the anti-idiotype-induced antibodies. $J$ Immunol 1991; 146: 188-193.

30. Schreiber JR. Anti-idiotype vaccines for immunity to bacterial polysaccharides: induction of functional antibodies to polysaccharide antigens of Pseudomonas aeruginosa. Springer Semin Immunopathol 1993; 15: 235-246.

31. Anders EM, Kapaklis-Deliyannis GP, White DO. Induction of immune response to influenza virus with anti-idiotypic antibodies. J Virol 1989; 63: 2758-2767.

32. Wake A. Genetically controlled natural resistance of mice to plague infection and its relationship to genetically controlled cell-mediated immune resistance. In: Skamene E, Kongshavn PAL, Landy M (eds) Genetic control of natural resistance to infection and malignancy. New York, Academic Press. 1980: $179-184$.

33. Field S, Pollack M, Morrison DC. Development of an antiidiotype monoclonal antibody mimicking the structure of lipopolysaccharide (LPS) inner-core determinants. Microb Pathog 1993; 15: 103-120.

34. Gulati S, McQuillen DP, Sharon J, Rice PA. Experimental immunization with a monoclonal anti-idiotype antibody that mimics the Neisseria gonorrhoeae lipopolysaccharide epitope 2C7. J Infect Dis 1996; 174: 1238-1248.

35. Schreiber JR, Dahlhauser P. Immunogenicity of tetanus toxoid conjugates of anti-idiotypes that mimic Pseudomonas aeruginosa surface polysaccharides. Infect Immun 1994; 62: 308-312.

36. Nazarova LS, Taranenko TM, Devdariani ZL et al. Morphological characteristics of Yersinia pestis lipopolysaccharide influence upon the murine organism. In: Problems of particularly dangerous diseases. Saratov, Russia. 1993: 147-157. 